

Alma Mater Studiorum - Università di Bologna DEPARTMENT OF ECONOMICS

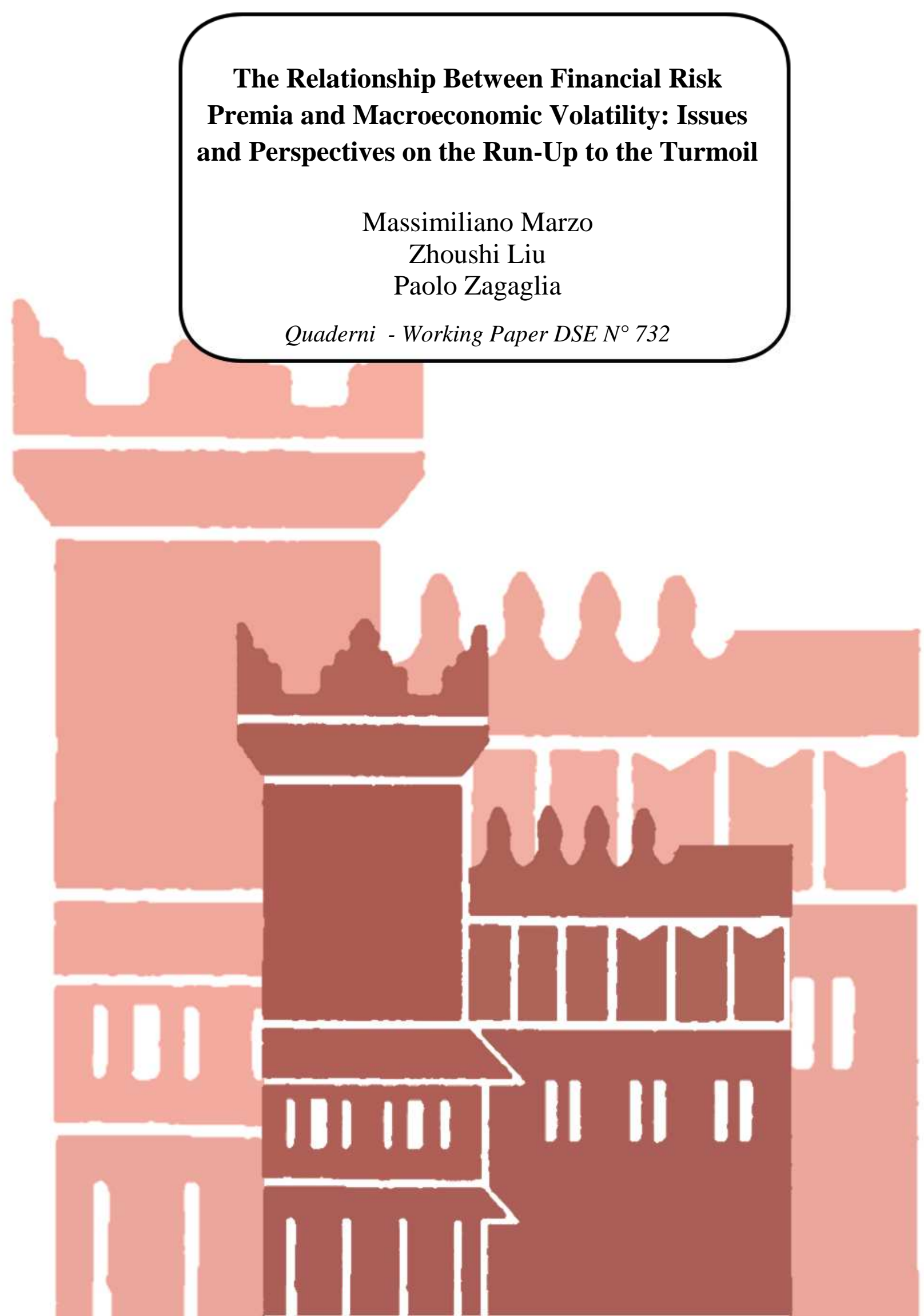




\title{
THE RELATIONSHIP BETWEEN FINANCIAL RISK PREMIA AND \\ MACROECONOMIC VOLATILITY: \\ ISSUES AND PERSPECTIVES ON THE RUN-UP TO THE TURMOIL
}

\author{
MASSIMILIANO MARZO, ZHOUSHI LIU AND PAOLOZAGAGLIA
}

\begin{abstract}
This note sketches the issues that arise while interpreting the relation between macroeconomic volatility and financial risk premia from the perspective of the standard consumption-based asset pricing model. The relation arises from the fact that all assets are priced by the same 'pricing kernel', given by the inter-temporal marginal rate of substitution in consumption of the representative investor. Since the pricing kernel is a function of aggregate consumption, financial risk premia are positively related to consumption growth volatility. Therefore, from the perspective of this workhorse often employed in the academic debate, the persistent reduction in macroeconomic volatility can be considered a cause for the low average risk premia prevailing during the so-called Great Moderation, namely the period preceding the recent turmoil in financial markets. We challenge this view by shedding light on the issues that generate an inconsistent interpretation of the model outcomes. In particular, since the consumption-based model is geared towards asset prices consistent with macroeconomic fundamentals, we argue that it is not suited for interpreting current developments where underestimation of risk may have subsidized asset prices. In particular, according to the evidence for the Great Moderation, the model view suffers from observational equivalence.
\end{abstract}

Keywords: asset pricing, macroeconomic volatility, Great Moderation.

JEL Classification: E43, G12.

\footnotetext{
'Marzo: Department of Economics, University of Bologna; massimiliano.marzo@unibo.it; Liu: Financial Economic Applications Team, Barrie \& Hibberg; zhoushi.liu@barrhibb.com; Zagaglia: Department of Economics, University of Bologna; paolo.zagaglia@gmail.com.

This material is for academic purposes only. The views expressed herein are solely those of the authors and should not be attributed to any public or private sector entity.
} 


\section{Introduction}

It is a fact that a 'Great Recession' has followed a 'Great Moderation' in the world economy (e.g., see Bernanke, 2004). This has coincided with a boom-bust cycle in financial markets worldwide. In other words, there was a build-up of tensions that took place in the markets until 2007. The accumulation of excessive risk-taking in the markets erupted in August 2007 in the form of freeze in interbank lending. Interestingly, the academic world has viewed the Great Moderation at the macroeconomic level as providing the foundations for a moderation of risk pricing in financial markets. This line of argument arises from the interpretation of a workhorse for asset pricing that is embedded in the current generation of frameworks used for macroeconomic analysis, the so-called 'general equilibrium models'.

In a consumption-based model, assets are priced by discounting future yields. Since the process of portfolio allocation affects the ability of households to consume, pricing assets involves a consistent planning of consumption across different points in time. As a result, the discount factor for assets is a function of consumption. A standard result is that asset returns in excess of the risk-free rate are related to consumption volatility. The economic interpretation is that investors require a systematic compensation for the risk arising from macroeconomic volatility. Like during the Great moderation, when asset price volatility has been low, as have been excess returns and risk premia.

We argue that there are several issues that prevent a consumption-based model from generating a reliable interpretation of asset price movements. In particular, we suggest that the interpretation suffers from observational equivalence. The experience of the period leading to the turmoil has been characterized by a systematic underestimation of risk because of an overall lack of market transparency. This has coexisted with a stable macroeconomic outlook.

This note is organized as follows. Section 2 reviews the foundations of consumption-based asset pricing. Section 3 proposes our critical line of argument.

\section{Financial risk premia in the consumption-based asset pricing model}

The representative consumer/investor maximizes expected intertemporal utility every period by splitting his budget between current consumption and investment in different asset classes for the purpose of future consumption. There is one risk-free asset, and a number of risky assets with random payoff $X_{t+1, i}$ in the next period and current price $P_{t, i}$. This structure can in principle apply to all assets, such as bonds, stocks, houses, derivatives or portfolios. For stocks, for instance, $P_{t, i}$ would denote the current ex-dividend price, and next period's payoff is given by the sum of the dividend $D_{t+1, i}$ and the then-prevailing ex-dividend price $P_{t+1, i}$. The (gross) returns of these assets are $R_{t+1, i}=X_{t+1, i} / P_{t, i}$ ithe riskfree asset has return $R_{t, f}($ risk-free interest rate).

For each asset $i$, prices are given as expectations of future payoffs, discounted by the investor's marginal rate of inter-temporal substitution in consumption, $M_{t+1}=\beta U^{\prime}\left(C_{t+1}\right) / U^{\prime}\left(C_{t}\right)$,

$$
P_{t, i}=E_{t}\left[X_{t+1, i} M_{t+1}\right]
$$


where $U^{\prime}$ is marginal utility, $\beta$ is the investor's time discount factor and $C$ denotes consumption. This follows as an optimality condition from the consumption/investment problem. The interpretation is that the expected marginal benefit of devoting one marginal unit of resources to asset iequals the current marginal utility loss of foregoing one unit of current consumption

Rewriting (1) provides an expression for risk premia, i.e. expected excess returns of risky assets over the risk-free rate

$$
E_{t}\left[R_{t+1, i}\right]-R_{t, f}=-\frac{\operatorname{Cov}_{t}\left[M_{t+1}, R_{t+1, i}\right]}{E_{t}\left[M_{t+1}\right]} .
$$

The important insight of this relation is that what matters for the risk premium of an asset is the covariance of that asset's return $R_{t+1, i}$ with consumer's marginal rate of substitution $M_{t+1}$ : the higher the covariance of returns with the marginal rate of substitution, the lower the risk premium. Assets that tend to give high returns when they are really appreciated - namely when marginal utility of future consumption is high, i.e. consumption growth is low - are attractive assets, for which investors require only a small risk premium. ${ }^{2}$ In contrast, assets that tend to pay off poorly when consumption growth is low, i.e. marginal utility is high (and - vice versa - that tend to pay off well, when consumption growth is high), require a large expected excess return such that investors are willing to hold them.

As the marginal rate of substitution Macts as a 'pricing kernel' for all assets, its own volatility restricts the possible magnitude of financial risk premia. Since $M$ is equal to the consumer's marginal rate of substitution and thus it is a function of consumption growth, the link between consumption volatility and financial risk premia becomes apparent. To see this nexus most clearly, consider the 'Sharpe ratio', i.e. the expected excess return per unit of the asset return's conditional volatility $\sigma_{t}\left[R_{t+1,}\right]$

$$
\frac{E_{t}\left[R_{t+1, i}\right]-R_{t, f}}{\sigma_{t}\left[R_{t+1, i}\right]}=-\rho_{i, M} \frac{\sigma_{t}\left[M_{t+1, i}\right]}{E_{t}\left[M_{t+1}\right]} .
$$

It depends on the correlation $\rho_{i, M}$ of the asset's return with the pricing kernel $M_{1}$ as well as the first and second moment of the latter.

Since the correlation coefficient $\rho_{i, M}$ ranges between -1 and 1, (3) implies that

$$
\frac{E_{t}\left[R_{t+1, i}\right]-R_{t, f}}{\sigma_{t}\left[R_{t+1, i}\right]} \leq \frac{\sigma_{t}\left[M_{t+1, i}\right]}{E_{t}\left[M_{t+1}\right]} .
$$

The link to consumption is directly apparent for the prominent example of the power utility function $U\left(C_{t}\right)=(1-\gamma)^{-1} C_{t}^{1-\gamma}$, for which (4) becomes approximately

$$
\frac{E_{t}\left[R_{t+1, i}\right]-R_{t, f}}{\sigma_{t}\left[R_{t+1, i}\right]} \leq \gamma \cdot \sigma_{t}\left[\Delta \log C_{t+1}\right] .
$$

\footnotetext{
${ }^{2}$ Extreme examples are insurance contracts that pay off in very bad states of the world: they can be viewed as assets for which investors are willing to accept a negative expected excess return.
} 
Equation (5) shows that the magnitude of financial risk premia is a positive function of the amount of macroeconomic risk given by the volatility of consumption growth $\sigma_{t}\left[\Delta \log C_{t+1}\right]$-a proxy for the quantum of non-diversifiable macroeconomic risk - and the willingness of consumers to bear that risk given by the relative risk aversion parameter $\boldsymbol{\gamma}$ - the individual price attached to the macroeconomic risk. The relation holds with equality for those assets of which the returns are perfectly negatively correlated with the pricing kernel. This holds for so-called efficient portfolios that give the maximum expected return for a given variance.

\section{A critical overview from a practitioner's perspective}

How does the consumption-based asset pricing model help to understand the build-up of tensions that led to the recent turmoil in financial markets? The model suggests that a permanent reduction of consumption volatility - which is typically positively correlated with output volatility - is associated with lower risk premia. In the same fashion, risk premia fall when the relative risk aversion of a representative investor falls. Along these lines, Lettau, Ludvigson and Wachter (2008) argue that the run-up in US stock market valuations in the 1990s was driven by a reduction in the equity risk premium, which was in turn caused by the Great Moderation in consumption growth volatility since the mid 1980s. ${ }^{3}$

Applying this logic to the interpretation of real-world events requires several qualifications.

Consumption-based pricing delivers a return that is consistent with pricing the sources of risk arising from changes in macroeconomic fundamentals. We can think of the observed asset prices as the sum of the price consistent with fundaments and a residual term. This 'residual' can measure a fitting problem. It is an 'observation' error, considering that the fundamental price is not known by the market. It is also an 'expectation' error since the model delivers a prediction for future asset prices.

This perspective raises two questions. The first issue has to do with the reason for fitting errors to arise. If the outcome of market actions arises from a notion of equilibrium consistent with the one embedded in the model, then no such a discrepancy should arise. The second question is related to how large and how persistent we should expect the fitting or observation errors to be. The experience of the transition from normal to turbulent market conditions between February and August 2007 suggests that these errors can be substantial. During this period, episodes of repricing or risk in certain market segments, such as the government bond market, corresponded with a stable macroeconomic outlook.

\footnotetext{
${ }^{3}$ We should stress that this is only one of the possible interpretations that consumption-based asset pricing can provide about changes in risk premia. For instance, movements in the coefficient of relative risk aversion can play a role. However, for the mere purpose of our discussion, we focus on consumption volatility.
} 
The point we are trying to make is that the interpretation of the prescription from the consumptionbased pricing model involves a number of issues which may lead to conclusions inconsistent with the very assumptions of the model itself.

The practical approach to model development in the risk-management industry can provide appealing insights into the interpretation of modelling outcomes. The private industry features several characteristics that are desirable from the perspective of a balanced use of models. A competitive offer of different modelling approaches is pervasive. Moreover, differently from the use of models produced by academics for the purpose of academic debate, there is no built-in alignment of interest between model producers and model users for risk management in the private sector. Let us draw an analogy with the case of general equilibrium models for the support of monetary policy decisions at central banks. As the New Keynesian paradigm represents the consensus academic view, models are produced by central bank economists, usually with scrutiny or advice from academics, to provide either policy advice or supporting arguments. It may be argued that the profit-maximizing nature of the risk management industry provides cases where modelling solutions are provided to third parties with an incentive to highlight and explain possible model shortcomings. This experience is relevant for our discussion because asset price modelling and forecasting is key for the risk management industry.

The left-hand side of equation (3) includes a Sharpe ratio. Standard practice in the risk-management industry puts special care in generating forecasts for the volatility of future returns that are reliable. This process involves setting up assumptions about the distribution of returns that can help to capture the likelihood of extreme events materializing. In other words, it is well clear in the industry that this involves forecasting the tails of the distributions of returns. Typically historical information is used to drive a prediction about future asset prices. Hence, the issue boils down to capturing the events of the past that present features relevant for the forecasting exercise. For instance, in estimating the average relation between consumption growth and the Sharpe ratio, how far long into the past should we go? Should we go back to the extreme events of the Great Depression? And what was the relation between consumption growth and the Sharpe ratio during the Depression period? Overlooking these issues can result in a failure to choose the parameters of a model consistently with the need to generate conservative forecasts. As a result, these issues are typically discussed at length in the risk-management industry.

There are deeper reasons to mistrust the standard academic interpretation of the prescription from consumption-based pricing. The transition to the current turmoil has shown that low excess returns can be due to an underestimation of the causes of movements in asset prices. In the jargon used earlier, this translates into a large fitting error. Part of the risk management industry also refers to this observation as arising from model risk. In other words, investors have used the wrong kind of model for pricing without taking into account the probability of this issue materializing. 
These considerations suggest that there can be rationales for the mispricing of risk to be systematic and persistent. In fact, it can be argued that a sound pricing of risk requires financial market participants to understand the structure of trading and the nature of the risks that can arise. Indeed investors may be unable or fail to understand these factors for several reasons. Markets may function in a nontransparent way. This point was also stressed by Jean-Claude Trichet in a speech delivered at the International Swaps and Derivatives Association in April 2007:

"Here, it should be acknowledged that the opacity of the credit derivatives market, and especially of structured synthetic instruments, is a potential source of concern. The complex interaction between cash instruments and credit derivatives has made it increasingly difficult to monitor where different, possibly sizeable, positions are taken and where risks are concentrated."

In this sense, knowledge of the microstructure factors can contribute to a better understanding of the determinants of risk. As argued by De Grauwe (2008) in an application of the idea of 'animal spirits', waves of optimism can contribute to the pattern of boom-bust cycle experienced during the market crashes of the part twenty years.

Summing up, we argue that the well-accepted academic interpretation of the macroeconomic causes of risk underestimation during the build-up of the turmoil is insightful about the shortcomings of the macro-based approach to asset pricing. This note provides a discussion of how a practitioner's point of view may help uncover the issues of an academic approach. In particular, we argue that the interpretation of asset price movements during the Great Moderation provided by consumption-based models suffers from observational equivalence.

\section{References}

Bernanke, B. (2004), The Great Moderation, remarks at the meetings of Eastern Economics Association, Washington, D.C., 20 February.

De Grauwe, P. (2008), Animal Spirits and Monetary Policy, CESifo Working Paper, 2418, October.

Lettau, M., Ludvigson, S. C., and Wachter, J. A. (2008), The declining equity premium: What role does macroeconomic risk play?, Review of Financial Studies, 21(4): 1653-1687,

Trichet, J.C. (2007), Some Reflections on the Development of Credit Derivatives, Keynote Address, $22^{\text {nd }}$ Annual General Meeting of the International Swaps and Derivatives Association, 18 April. 


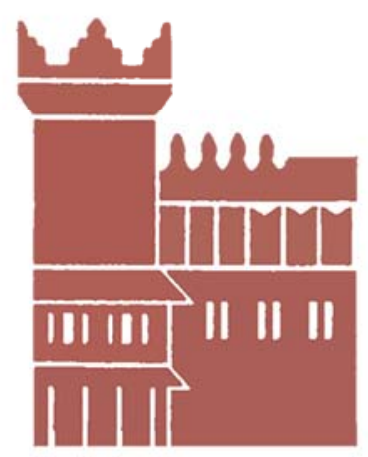

Alma Mater Studiorum - Università di Bologna DEPARTMENT OF ECONOMICS

Strada Maggiore 45

40125 Bologna - Italy

Tel. +39051 2092604

Fax +390512092664

http://www.dse.unibo.it 